present acute medical and surgical problems may be unsympathetic to the rather different problems of treating psychiatric patients.

Mental hospitals in some form are likely to remain in order to provide asylum and long-term custodial (an unfashionable but necessary word) and therapeutic care, with special facilities for education, training, and rehabilitation. Will the development of large general hospital units provide opportunity for sharing medical and nursing staffs, or will they merely deprive the mental hospitals of their acute admission and treatment units? The second possibility would increase the stigma of admission to mental hospital and add to the difficulties in recruiting medical and nursing staff. ${ }^{1}$ One suggestion made is that patients who do not require care in a psychiatric unit for acute cases should be managed in asylums staffed by non-medical specialists, with general practitioners providing such medical care as is required.

Perhaps less attention should be paid to details of institutional structure and more to overall patterns of care. With a few notable exceptions the present divisions between hospital, general practitioner, and local authority have been associated with a failure to provide flexible, continuous, and comprehensive care for all psychiatrically ill people. Community care has been welcomed on the one hand as a panacea and on the other rejected as a failure, yet comprehensive community care has rarely been achieved, nor have its consequences been evaluated. $^{3}$ Psychiatry cannot be practised entirely within the boundaries of any one kind of hospital, and its services must be related to the whole needs of defined populations if overlapping but incomplete patterns of service are to be avoided.

\section{Symposium on Thyroid Gland}

A symposium on the thyroid gland was arranged by the Association of Clinical Pathologists last October. The organizers were Dr. G. K. McGowan and Dr. M. Sandler, and Professor N. F. Maclagan took the chair. Its main aim was to provide an up-to-date review of the subject, and most speakers reported their own recent advances in the field. Now its proceedings appear as an unusually interesting special supplement to the Fournal of Clinical Pathology. ${ }^{1}$

Two conclusions can be drawn from the symposium which are of particular importance to hospital laboratories investigating thyroid disease. Firstly, the diagnostic value of estimating the plasma protein-bound iodine (P.B.I.) can be increased if the result is assessed along with some measurement of thyroxine-binding protein capacity such as the resin uptake of ${ }^{131}$ I-labelled triiodothyronine. A combination of the two results allows calculation of a free-thyroxine index, which gives a very good indication of thyroid status. Secondly, the diagnostic value of tests of thyroid radioiodine uptake is greatly enhanced by measuring the level of plasma inorganic iodine, for this allows the absolute iodine uptake by the thyroid to be calculated. This refinement corrects for changes in thyroid uptake of radioiodine caused by alterations in plasma levels of inorganic iodine rather than by changes in thyroid activity.

Some recent advances reported at the symposium warrant brief mention. Dr. Th. Lemarchand-Béraud describes a

1 f. clin. Path. Suppl., 1967, 20, 309-414 method of determining thyroid-stimulating hormone (T.S.H.) in human blood by the technique of radioimmunoassay. This method is sensitive enough to detect T.S.H. in the blood of normal persons. Professor E. M. McGirr presents evidence for a sixth inherited intrathyroidal defect in the formation and release of thyroid hormone caused by defective protease activity, which interferes with the liberation of thyroxine from thyroglobulin. Drs. I. M. Roitt and G. Torrigiani describe a sensitive and specific method for radioimmunoassay of thyroglobulin by which they have detected thyroglobulin in the sera of $60 \%$ of healthy persons. Thyroglobulin reaches the blood stream by way of the lymphatics. The implication of this finding is far-reaching. Thyroglobulin cannot now be regarded as a " secluded" protein, and thyroid autoimmunity must arise in ways other than by release of antigen, most probably owing to a defect of "selfrecognition" immunologically.

The editors have supplied a glossary which will be very useful to readers who are new to this field. Of two appendices, one lists the factors other than thyroid disease which affect the protein-bound iodine and other thyroid-function tests, and the other indicates the usual results obtained in various thyroid disorders. The proceedings of this symposium will be invaluable to all clinicians investigating patients with thyroid disease. The critical evaluation of tests of thyroid function will certainly help to improve the standards of diagnosis and the control of treatment.

\section{Cadmium Poisoning}

From time to time episodes of acute cadmium poisoning are reported, emphasizing the potential toxicity of this metal and its salts. In a recent incident ${ }^{1}$ five workmen who were dismantling a frame of girders by cutting steel bolts with an oxyacetylene burner were affected. The bolts had been plated with cadmium to resist corrosion, and as a result the men were exposed to cadmium oxide fume in a confined space. The fume was not sufficiently irritant to make them stop work, but a few hours after exposure all five men became ill with malaise, shivering, sweating, an irritant cough, pain in the chest, and dyspnoea. The initially mild symptoms were followed by the development of pulmonary oedema and pneumonitis, and one man died on the fifth day after exposure. At necropsy the lungs, in addition to massive pulmonary oedema, contained thrombi in the arteries, while histological examination showed cellular proliferation and metaplasia in the alveoli. The kidneys had undergone bilateral cortical necrosis with widespread tubular degeneration and glomerular infarction.

Men exposed for longer periods to lower concentrations of cadmium oxide fume or dust or to cadmium sulphide dust may also develop disease of the respiratory system and of the renal tract. ${ }^{2}$ Such exposure may occur during the manu-

1 Beton, D. C., Andrews, G. S., Davies, H. J., Howells, L., and Smith, G. F., Brit. f. Industr. Med., 1966, 23, 292.

- Friberg, L., A.M.A.. Arch. industr. Hlth., 1957, 16, 27.

- Bonnell, J. A., Kazantzis, G., and King, E., Brit. f. industr. Med. $1959,16,135$.

- Smith, J. P., Smith, J. C., and McCall, A. J., f. Path. Bact., 1960, 80, 287.

- Butler, E. A., Flynn, F. V., Harris, H., and Robson, E. B., Clin. Chim. Acta., 1962, 7, 34 .

- Piscator, M., Arch. environm. Hlth., 1966, 12, 335 and 345.

- Kazantzis, G., Flynn, F. V., Spowage, J. S., and Trott, D. G., Quart. f. Med., 1963, 32, 165. 
facture of cadmium-containing alloys, alkaline accumulators, cadmium-based pigments, or from any process where cadmium or cadmium-plated metal is heated to evolve fume. Cadmium is also used as a neutron absorber in nuclear reactors and is a constituent of some silver polishes.

Many of the workers exposed in the past to cadmium fume developed progressive dyspnoea, and some died after years of incapacity. Respiratory function tests have shown the presence of obstructive airways disease, and severe emphysema has been found in the lungs at necropsy. ${ }^{34}$ Most cadmium workers who become breathless have also developed proteinuria, while others have developed proteinuria without respiratory symptoms. While damage to the kidneys usually causes less incapacity than that to the lungs, some patients develop renal colic owing to the formation of stones, and a few patients have died from renal failure. The proteinuria in these patients is chronic, mild, and indistinguishable on electrophoretic examination from that occurring in patients with various renal tubular disorders. ${ }^{5}$ Concentration of the urinary colloids shows a relatively low albumin fraction with a predominance of $\alpha_{2}$ and $\beta$ globulins. Most of the proteins present are of relatively low molecular weight, and their appearance in the urine is believed to result from impaired reabsorption of proteins that are normally present in the glomerular filtrate. ${ }^{6}$ Other abnormalities described have been glycosuria, aminoaciduria of renal origin, hypercalciuria, and impairment of concentrating ability and of acid excretion, all of which point to dysfunction of the renal tubules. ${ }^{7}$

The manifestations of acute cadmium poisoning may be delayed some hours after exposure, whilst chronic poisoning usually develops insidiously at least two years after the start of exposure and occasionally some time after its cessation. The effects of this toxic element are irreversible at present, so that it is important to be aware of this uncommon condition and how to prevent exposure to cadmium fume and dust.

\section{Autotransfusion}

Recently in Nigeria A. Akinkugbe ${ }^{1}$ has reported on the use of autotransfusion as a resuscitative measure in cases of ruptured ectopic pregnancy. Applicable to any case of severe intraperitoneal bleeding, autotransfusion is the simple expedient of collecting the patient's own shed blood from the peritoneal cavity, straining off any clot, and injecting it back into the veins. Especially in remote areas where blood donor or blood bank facilities are not available it can be a valuable adjunct to recovery.

Autotransfusion is not a new method of treatment, but, chiefly because donor's blood is usually available, it has lost favour. F. Stabler, ${ }^{2}$ in 1934, reported the treatment of 13 patients with it, and F. P. Logan, ${ }^{3}$ in 1948, in South Africa, recorded 40 cases, with recovery in all. In recent years Chassar Moir $^{45}$ has repeatedly advocated autotransfusion. $\mathrm{He}$ believes it is a valuable method of emergency resuscitation, especially in regions where blood banks are unknown. He states that he has used it " on many occasions" and "feels it a duty to demonstrate the method" to his students. He

\footnotetext{
1 Akinkugbe, A., f. Nigeria med. Ass., 1966, 3, 379.

2 Stabler, F., f. Obstet. Gynaec. Brit. Emp., 1934, 41, 768.

S Logan, F. P., S. Afr. med. F., 1948, 22, 793.

- Moir, J. C., Lancet, 1960, 1, 60.
}

quotes B. Markowski, who in British Honduras used autotransfusion in 100 cases, with survival in all but one.

A practical advantage of autotransfusion is the ease and speed with which it can be carried out, without the timeconsuming grouping and cross-matching of blood. The blood which has collected in the abdominal cavity is simply ladled out with a galley pot or other suitable vessel and collected in a sterile flask containing $3.8 \%$ sodium citrate solution to make a proportion of nine parts of blood to one of solution. (If available, the "standard" bottle for blood donors containing $2 \mathrm{~g}$. disodium citrate and $3 \mathrm{~g}$. dextrose in $120 \mathrm{ml}$. water is convenient for the purpose.) When full the bottle is connected to the apparatus for intravenous infusion of saline set up before operation.

Only recently shed fluid blood is suitable for autotransfusion. But the method is intended for the collapsed patient with sudden intraperitoneal haemorrhage-the " acute" type of ruptured tubal pregnancy in which such blood is available in abundance. It is less suitable, and indeed it is not necessary, in the commoner "subacute" case (tubal mole), when the blood is old and firmly clotted.

Naturally, when donor blood is readily available, autotransfusion is apt to be forgotten, but this method of resuscitation, so simple and at the same time so effective, deserves to be better known and more widely used.

\section{Construction of Vagina}

The vagina may be congenitally absent or it may have been totally or partially excised for cancer of the uterine body, uterine cervix, or the vagina itself.

When the vagina is congenitally absent the uterus is usually absent also, and these patients have primary amenorrhoea. The ovaries are present and the girls are normally feminized. Occasionally-about 30 cases have been reported-a functional uterus is present which is capable of carrying a baby to term, and in fact has actually done so after a vaginal construction. Five to ten new cases of congenital absence are seen annually in the London hospitals which offer specialized surgery for this condition. Investigation of the patient should include intravenous pyelography to exclude associated abnormalities of the urinary tract, an examination under anaesthesia, and sometimes an exploratory laparotomy.

Congenital absence of the vagina is best treated by a McIndoe type of epithelial inlay operation. ${ }^{1}$ A gynaecologist incises the perineum and dissects a retroperitoneal cavity. A plastic surgeon then introduces a rather thick partial-thickness skin graft from a thigh into this cavity round a prosthesis, and the labia minora are closed over it. When hard prostheses were used, fistulae, haematomata with loss of graft, urinary infections, renal stones, and extrusion of the vaginal mould were fairly common complications. ${ }^{2}$ Soft prostheses are now available, the simplest of which is a cylindrically shaped piece of polyurethane plastic sponge, and with it postoperative complications are rare. ${ }^{3}$ As with all epithelial inlays, regular dilatation or constant maintenance of the original cavity size is necessary at first. The operation is therefore best performed three months before marriage, and once the graft has " taken"

\footnotetext{
1 McIndoe, A. H., and Banister, J. B., F. Obstet. Gynaec. Brit. Emp., $1938,45,490$.'

S Simmons, C. A., Proc. roy. Soc. Med., 1959, 52, 953.

- Jayes, P. H. Ann. roy. Coll Surg. Engl, 1966, 38, 210.

- Pratt, J. H., and Smith, G. R., Amer. F. Obstet. Gynec., 1966, 96, 31.
} 